\title{
Editorial \\ Ambitions and Critiques of Restorative Justice Post COVID-19
}

\author{
Theo Gavrielides ${ }^{1,2}$ (D)
}

check for

Citation: Gavrielides, Theo. 2022.

Ambitions and Critiques of

Restorative Justice Post COVID-19.

Laws 11: 6. https://doi.org/

10.3390/laws11010006

Received: 6 January 2022

Accepted: 10 January 2022

Published: 11 January 2022

Publisher's Note: MDPI stays neutral with regard to jurisdictional claims in published maps and institutional affiliations.

Copyright: (C) 2022 by the author. Licensee MDPI, Basel, Switzerland. This article is an open access article distributed under the terms and conditions of the Creative Commons Attribution (CC BY) license (https:// creativecommons.org/licenses/by/ $4.0 /)$.
1 Restorative Justice for All (RJ4All) International Institute, London SE16 2LJ, UK; t.gavrielides@rj4all.org 2 School of Psychology, University of East London, London E16 2RD, UK

\begin{abstract}
The COVID-19 pandemic did not only change how we work with others and deliver public services, but also our very way of living. Furthermore, the way we view and experience conflict and violence will never be the same. Therefore, changes anticipated in relation to justice and criminal justice will be unprecedented, with criminal justice institutions such as prisons, courts and probation to be reviewed whether for financial, political or health and safety-related reasons. This Editorial introduces this Special Issue, which focuses on highlighting both the ambitions but also critiques of the role that restorative justice can play in the post COVID-19 era.
\end{abstract}

Keywords: restorative justice; COVID-19; social policy reform; new forms of violence

\section{Conflict and Violence in the Post COVID-19 Era}

We now have enough evidence to substantially claim that the COVID-19 pandemic caused a series of long-lasting socio-economic and health impacts (Gavrielides 2021; Bernadas and Yarcia 2021), some even warning that this impact is comparable only with the one that followed World War II (Gavrielides 2021). Furthermore, scientists at Oxford's Leverhulme Centre for Demographic Science released data suggesting that the COVID-19 pandemic triggered life expectancy losses not seen since World War II in Western Europe, and exceeded those observed around the dissolution of the Eastern Bloc in central and Eastern European countries (Aburto et al. 2021).

Here, I claim that, along with these impacts, COVID-19 has also brought a change in how conflict and violence are viewed and indeed experienced, and the need to adapt the way they are managed. My claim refers not only to interpersonal conflict and violence, but also violent phenomena taking place between communities and groups, as well as nations.

Violence has traditionally taken the form of a physical encounter, typically categorized according to the relationship between the victim and the perpetrator, as well as the location in which it takes place (Rosenberg et al. 1992). The World Health Organisation (WHO) defines violence as "The intentional use of physical force or power, threatened or actual, against oneself, another person, or against a group or community that either results in or has a high likelihood of resulting in injury, death, psychological harm, maldevelopment or deprivation" (World Health Organisation 2002, p. 5). The World Health Organisation (2002) accepts three broad categories of violence, based on the characteristics of those committing the violent act: (1) self-directed violence, (2) interpersonal violence, and (3) collective violence. According to the $\mathrm{WHO}$, collective or group violence is subdivided into social, political, and economic violence.

Looking at the post COVID-19 crime statistics, as well as unpublished victim stories covered in the media from around the world ${ }^{1}$, we observe two new trends of violence and conflict.

The first trend relates to the lockdowns and the shift in the manifestation of interpersonal relationships, which had to adapt to new environments and endure challenges never before experienced; for example, it is a fact that domestic violence incidences as

1 See, for instance, https:/ / www.bbc.co.uk/news / 56463680 (accessed on 5 January 2022). 
well as conflicts between family members, lovers, friends, and relatives increased (e.g., see Sharma and Borah 2020), these phenomena also having taken new forms, including an increase in their severity. Combined with an increase in alcohol consumption and the deterioration of mental health within family members, it is not surprising that official government statistics indicate an increasing concern regarding the impact of family violence and the rise in its cases (see, for example, the Office for National Statistics 2020). Within these statistics, children and young people seem to have been affected the most, especially in relation to the lockdowns' mental health impacts, children, for example, having been recorded as one of the primary groups of new perpetrators on the rise, often directing their violence against fragile or vulnerable family members, including their grandparents (the Office for National Statistics 2020).

The second trend relates to the cyber environment that COVID-19 and our governments' social distancing measures forced us to adopt as the norm for our social interactions. In this cyber space, conflict and violence have taken new dimensions with online bullying, for example, spiralling, and new forms of financial crimes being committed ${ }^{2}$. During the lockdowns, close to $100 \%$ of our business meetings and most of our personal encounters happened online, while it is expected that over $70 \%$ of these meetings will continue to take place online for the foreseeable future. We have also accepted the reality of holding events, academic conferences, business negotiations, and even wedding ceremonies online! However, with this form of "meetings" come new forms of conflict, and I fear they may be concealed and more cancerous than their overt versions.

The truth is that whether we do or do not accept that violence and conflict are taking new forms and dimensions, there can be no doubt that, along with the health and social care reforms that are already taking place, we should expect reformed criminal justice systems. We will also soon realise that some tools are not fit for purpose, and that the net must be widened to catch what is slipping through its holes.

\section{The Role of Restorative Justice}

In this international changing policy and institutional landscape, where reforms are taking place to allow cost-effective and up-to-date interventions, restorative justice advocates found space to argue in favour of this historical paradigm (Gavrielides 2011). For example, Velez et al. argued in favour of remote restorative practices for conflicts that take place in virtual school settings (Velez et al. 2021), presenting evidence that was collected during the COVID-19 pandemic to claim that virtual restorative justice can have preventative and even controlling effects on anti-social behaviour.

I have always been transparent regarding my role and relationship with restorative justice, having always been dominated by my passion to speak from evidence and challenge the restorative justice movement, both in relation to the potential and the limitations of the restorative justice theory and practice (Gavrielides 2007, 2020).

Therefore, I followed up Velez's research in a recent interview as a part of my "\#RJ webinar" series titled "Virtual Restorative Justice" ${ }^{3}$, in which one of the questions I raised was around issues of training and capacity building. For example, if restorative justice is being adapted to the virtual space to deal with new phenomena of conflict and violence, then how prepared are its practitioners? Most of their training assumes physical contact, or harms committed in the traditional manner. When bringing people together in a virtual space, how equipped are restorative justice practitioners to detect the dynamics that would allow the necessary emotional reactions that make restorative encounters unique in their contribution to prevention and control?

These are only examples of my concerns, and I was thrilled to see a contribution by Prof. Velez in this Special Issue. His evidences, along with those submitted by Brown, provide

2 See, for instance, https://www.huronconsultinggroup.com/insights/financial-crime-risks-post-covid-19 (accessed on 5 January 2022).

3 https:/ / www.youtube.com/watch?v=QcBCbgdqMFQ\&t=138s (accessed on 5 January 2022). 
us the chance to critically reflect on the role and limitations of restorative justice in school settings, an important environment that is often neglected in the criminal justice literature. Obviously, it is too early to safely claim that their early research can satisfy historical concerns relating to the implementation and philosophical justification of restorative justice, especially in the new context of COVID-19. However, they do provide a good starting point for a much-needed debate.

This debate also needs to be triggered within the wider criminal justice sector, as I fear that unsubstantiated claims and fears around costs may lead to yet another restorative justice roll out, which lacks evidences and the buy in from its users (Gavrielides 2021). It is with this fear that I agreed to edit this Special Issue, with the hope of it providing the foundation for an evidence-based social policy, independent of location.

Funding: This research received no external funding.

Conflicts of Interest: The author declares no conflict of interest.

\section{References}

Aburto, José Manuel, Jonas Schöley, Ilya Kashnitsky, Luyin Zhang, Charles Rahal, Trifon I. Missov, Melinda C. Mills, Jennifer B. Dowd, and Ridhi Kashyap. 2021. Quantifying impacts of the COVID-19 pandemic through life-expectancy losses: A population-level study of 29 countries. International Journal of Epidemiology. [CrossRef]

Bernadas, Jan Michael Alexandre, and Lee Edson Pacudan Yarcia. 2021. Guest editorial. International Journal of Human Rights in Healthcare 14: 189-91. [CrossRef]

Gavrielides, Theo. 2007. Restorative Justice Theory E Practice: Addressing the Discrepancy. Helsinki: Heuni.

Gavrielides, Theo. 2011. Restorative Practices: From the Early Societies to the 1970s. Internet Journal of Criminology. Available online: http:/ / restorativejustice.org/rj-library/restorative-practices-from-the-early-societies-to-the-1970s/10428/\#sthash. 4JHoxvV9.dpbs (accessed on 5 January 2022).

Gavrielides, Theo. 2020. Restorative Justice Theory and Practice: Addressing the Discrepancy, 2nd ed. London: RJ4All Publications.

Gavrielides, Theo. 2021. Power, Race \& Justice: The Restorative Dialogue We Won't Have. Abingdon: Routledge.

Office for National Statistics. 2020. Domestic Abuse during the Coronavirus (COVID-19) Pandemic, England and Wales: November 2020. London: ONS.

Rosenberg, Mark L., Patrick W. O'Carroll, and Kenneth E. Powell. 1992. Let's Be Clear: Violence Is a Public Health Problem. Journal of the American Medical Association 267: 3071-72. [CrossRef] [PubMed]

Sharma, Amalesh, and Sourav Bikash Borah. 2020. COVID-19 and Domestic Violence: An Indirect Path to Social and Economic Crisis. Journal of Family Violence, 1-7. [CrossRef]

Velez, Gabriel, Madeline Hahn, and Antonio Butler. 2021. Opportunities and challenges for race equality in the age of COVID-19: Comparing virtual with face-face approaches to restorative practices in schools and communities. In Comparative Restorative Justice. Edited by Gavrielides Theo. New York: Springer.

World Health Organisation. 2002. World Report on Violence and Health. Geneva: WHO. 